\title{
In the Classroom
}

\section{An Emerging Pedagogical Approach to Teaching Pragmatic Formulas}

\section{Alisa Zavialova}

A good mastery of a range of formulaic sequences appears to be an important component of successful language learning (Wood, 2015; Wray, 2002). Certain formulaic sequences, known as pragmatic formulas, play a vital role in developing second language pragmatic competence, as they are crucial for successful speech act realization (Bardovi-Harlig, 2012). However, this category of formulaic language has been rather neglected in ESL pedagogy. To date, approaches to teaching formulaic language and pragmatics mainly use awareness-raising techniques; this approach, however, lacks potential for retention of formulaic sequences in learners' long-term memory (Boers \& Lindstromberg, 2009). This article reports on a 6-hour course that was taught to 4 intermediate ESL students enrolled in one of the Language Instruction for Newcomers to Canada (LINC) programs in Ontario. The course followed a refined approach to teaching pragmatic formulas that went beyond awareness-raising and consisted of three teaching phases: awarenessraising, deep cognitive engagement, and practice. Results of the final assessment showed that 2 participants expanded their repertoires of both refusal and thanking pragmatic formulas, while the other 2 participants improved their performance in the thanking speech acts.

Une bonne maitrise d'une gamme de formules semble être une composante importante de l'apprentissage réussi d'une langue (Wood, 2015; Wray, 2002). Certaines formules, qu'on appelle des formules pragmatiques, jouent un rôle essentiel dans le développement de la compétence pragmatique en langue seconde puisqu'elles sont cruciales à la réalisation des actes de langage (Bardovi-Harlig, 2012).Toutefois, la pédagogie en ALS a plutôt négligé cette catégorie de formules. Jusqu'à présent, les approches en enseignement des formules et de la pragmatique reposent surtout sur des techniques consistant à faire prendre conscience des expressions. Cependant, cette approche n'est pas susceptible d'aider les étudiants à retenir les formules à long terme (Boers $\mathcal{E}$ Lindstromberg, 2009). Cet article rend compte d'un cours de 6 heures enseigné à 4 étudiants intermédiaires en ALS inscrits à un programme de CLIC (Cours de langue pour les immigrants au Canada) en Ontario. Le cours a adopté une approche plus poussée à l'enseignement des formules pragmatiques qui dépassait la conscientisation et qui s'est déroulé en trois étapes: la prise de conscience, un engagement cognitif profond et la pratique. Les résultats de l'évaluation finale indiquent que 2 participants ont élargi leur répertoire de 
formules pragmatiques visant le refus et celles visant le remerciement, alors que les 2 autres ont amélioré leur rendement en matière de formules de remerciement.

KEYWORDS: instructional pragmatics, pragmatic formulas, deep cognitive processing.

Formulaic language is an umbrella term that may refer to various types of multiword units such as proverbs, collocations, lexical bundles, and many others (Weinert, 2010). Specialists agree that for a sequence to be considered formulaic, it has to be continuous or discontinuous, contain two or more words, have a single meaning or perform a single pragmatic function, and be uttered in a phonologically coherent manner (Wood, 2015; Wray, 2002). A good mastery of a range of formulaic sequences appears to be an important component of successful second language (L2) learning. According to Wray (2000), formulaic sequences can facilitate fluency of expression and help second language speakers save effort in spontaneous speech processing. Certain formulaic sequences have a valuable role in augmenting L2 pragmatic competence. ${ }^{1}$ These sequences can be referred to as pragmatic formulas, ${ }^{2}$ also known as routine formulae or situation-bound utterances (Kecskes, 2010). Examples include sequences like good morning, see you soon, or hold the line, please (Kiefer, 1996). Pragmatic formulas provide verbal means for mastering various social situations (Coulmas, 1979), serve as valuable pragmalinguistic ${ }^{3}$ resources for L2 learners, and are accepted as the most appropriate linguistic ways of "doing things" by the target language speech community (BardoviHarlig, 2012).

Instructional pragmatics currently lacks evidence-based approaches to teaching pragmatic formulas. In particular, major pedagogical models of teaching speech acts (e.g., Martínez-Flor \& Usó-Juan, 2006) make only vague references to pragmatic formulas. Furthermore, instructional pragmatics mainly follows the awareness-raising approach and lacks more structured and controlled activities to help learners make form-meaning connections to successfully interpret and produce target language utterances in a given context. It has been claimed that awareness-raising alone has a weak potential for the retention of formulaic sequences in learners' long-term memory (Boers \& Lindstromberg, 2009). Therefore, more pedagogical intervention studies that link knowledge of formulaic language with well-established methods like task-based teaching and focus on form are needed (Wood, 2015).

To address the abovementioned research gaps, I designed and taught a six-hour course focused on refusal (e.g., I won't be able to make it) and thanking (e.g., I appreciate it) pragmatic formulas. This course followed a more refined approach to teaching pragmatic formulas that went beyond awareness-raising and consisted of a carefully planned instructional sequence. In what follows, I discuss the weaknesses of the current approaches to teaching formulaic language and pragmatics. Next, some key examples of teaching 
techniques that can be used to complement awareness-raising are reviewed. Lastly, a detailed description of the course is presented along with a discussion of potential pedagogical implications of the suggested approach.

\section{Formulaic Language in L2 Teaching}

In formulaic language pedagogy, teaching methods that follow the awareness-raising approach based on the noticing hypothesis (Schmidt, 1990) are commonly reported in the literature (e.g., Boers, Eyckmans, Kappel, Stengers, \& Demecheleer, 2006). It is assumed that an enhanced awareness of formulaicity will foster independent learning because L2 learners will be more inclined to notice formulaic sequences in the target language. Participants in the studies that use attention directing and stimulating retention types of instruction were prompted to remember particular vocabulary items so that they could be stored in the mental lexicon. This can be done with the help of specific teaching techniques, such as text chunking, collocation recognition, L1 comparative translations, and so on (e.g., Peters, 2012; Webb \& Kagimoto, 2011). Moreover, the effects of drawing learners' attention to mnemonic effects of formulaic sequences as well as encouraging learners to notice alliteration in lexical chunks have been researched quite extensively (e.g., Boers, Eyckman \& Stengers, 2006; Lindstromberg \& Boers, 2008).

However, the majority of studies that used the awareness-raising approach showed weak potential for the retention of formulaic sequences in learners' long-term memory. Experts agree that in order to achieve better results in formulaic language acquisition and make classroom instruction more efficient, teaching should include activities involving deep cognitive processing or cognitive engagement (Boers \& Lindstromberg, 2009). Deep cognitive engagement is based on the notion of elaboration that requires learners "to engage in a cognitive activity with regard to a particular lexical item that goes beyond this item merely being noticed" (Boers \& Lindstromberg, 2009 , p. 22). The two main types of deep cognitive processing are semantic elaboration and structural elaboration. Semantic elaboration may include activities exploiting images, identifying the source of the target expression, or grouping phrasal verbs according to the theme of an underlying conceptual metaphor. Structural elaboration involves designing activities featuring such phonological features as alliteration and assonance in the target formulaic expressions (Boers \& Lindstromberg, 2009). This approach seems to be more effective for acquisition and long-term retention of formulaic language items.

\section{Pragmatic Formulas in L2 Teaching}

The majority of the studies that used the deep cognitive processing approach have focused on teaching collocations and idioms. Unlike collocations (e.g., 
garage sale) or idioms (e.g., make both ends meet, kick the bucket), whose meanings are not context-dependent, the use of pragmatic formulas is determined by a particular social context (e.g., I wish I could help, but; thanks for your understanding). Moreover, pragmatic formulas have a sentence-like grammatical structure (Pawley, 2007), which may make the process of their acquisition and mental processing more difficult for L2 learners. Therefore, more teaching intervention studies are needed in order to explore the efficacy of the deep cognitive processing for teaching pragmatic formulas.

To date, explicit teaching and raising metapragmatic awareness about sociopragmatic and pragmalinguistic aspects of pragmatic formulas are the most popular approaches reported in the literature. It is indeed important that learners be aware of the contextual factors that impact speakers' choices of linguistic structures. However, awareness-raising is not sufficient for successful acquisition of L2 pragmatics (Bardovi-Harlig, 2009). Learners also need to practice participating in speech events and learn how to negotiate meanings in order to produce contextually appropriate target language structures (Long, 1996, as cited in Kasper, 2001). For example, in studies conducted by Tateyama (2001), Yoshimi (2001), and Rose and Kwai-fun (2001), participants were prompted to either pay attention to formulas when watching a video or review handouts with detailed explanations of contexts and proper use of formulas combined with teachers' detailed metalinguistic explanations and guidance. The results of these studies have revealed a weak potential of awareness-raising to facilitate retention of a wide range of formulas (Yoshimi, 2001). Research shows that at least four factors need to be made salient to L2 learners and make pragmatics instruction more effective: (a) a pragmalinguistic form; (b) its function; (c) a situation in which such form is required; and (d) the particular power, distance, and imposition values involved (Fukuya \& Clark, 2001).

\section{Complementing Awareness-Raising}

The pedagogical novelty of the present course is that it proposes a more refined approach to teaching pragmatic formulas by integrating various techniques from both formulaic language and pragmatics pedagogy. When designing my course, I drew on the following teaching techniques that may complement awareness-raising in either formulaic language or pragmatics instruction:

- Semantic and structural elaboration involves such activities as exploiting images, identifying the source of the target expression, or featuring phonological features of the target formulaic sequences such as alliteration and assonance (Boers \& Lindstromberg, 2009);

- Ethnography and speech act analysis involves encouraging students to become ethnographers and data collectors as well as analyze each speech act in terms of its semantic formulas ${ }^{4}$ (Cohen, 2005); 
- Contextualized input tasks and guided metapragmatic noticing involves encouraging students to predict situations where target formulas may occur; afterwards, the students are presented with written input illustrating how formulas are used in context (Bardovi-Harlig \& Vellenga, 2012);

- Metapragmatic instruction involves any metapragmatic comment provided by the teacher in response to a student's performance; it may also be combined with whole-class metapragmatic discussion facilitated by the teacher (Kasper, 2001);

- Pragmalinguistic recast is a specific type of corrective feedback that implies reformulation of an utterance that is pragmatically inappropriate or grammatically inaccurate (Fukuya \& Zhang, 2002).

A detailed description of the course is presented below.

\section{Course Description}

The course was taught over a 2-week period to four intermediate ${ }^{5}$ adult ESL students enrolled in one of the Language Instruction for Newcomers to Canada (LINC) programs in Ontario. The students came from diverse linguistic and cultural backgrounds. The group comprised two Mandarin speakers, one Tamil speaker, and one Berber (Amazigh) speaker. I met with the students outside regular LINC classes. During initial assessment, each student participated in six role-plays focused on three thanking and three refusal speech acts. As shown in Figure 1, the course consisted of three teaching phases, two hours per session; each phase, in turn, consisted of several microlevel teaching activities. During final assessment conducted at the end of the course, students participated in six role-plays based on slightly changed scenarios. All data were audio-recorded and transcribed to compare students' performance before and after the instruction.

The scenarios of the role-plays included three topics requiring both formal and informal registers: interacting with a friend, interacting with a sales agent, and interacting with a manager. These topics are consistent with LINC Curriculum Guidelines for levels 5-7 (Hajer, Kaskens, \& Stasiak, 2007). According to this document, key oral communication skills LINC students are to develop include social interaction skills, workplace and customer service relations skills, ability to resolve conflicts, and, finally, ability to engage in various kinds of formal and informal meetings. The speech acts of refusal and thanking were chosen accordingly.

The two objectives of the six-hour course were to

1. explore ways in which pragmatic formulas can be taught within a limited time period;

2. propose a more refined approach to teaching pragmatic formulas and enhancing L2 pragmatic competence by integrating various techniques from both formulaic language and pragmatics pedagogy. 


\section{Phase 1}

1. Metapragmatic explanations and corpus consultation. In the beginning of this phase, each participant received two lists, the first with 40 refusal pragmatic formulas and the second with 34 thanking pragmatic formulas. These formulas were extracted from the Native Speaker Corpus (NSC) collected in my previous study (Zavialova, 2016). The students were encouraged to review the formulas from both lists. Afterwards, the students received explicit explanations with regard to the idiomatic nature of the target formulas supported by several key examples from the NSC. The students were instructed to bring these lists to each of the subsequent lessons.

\section{Initial assessment (pre- instruction)}

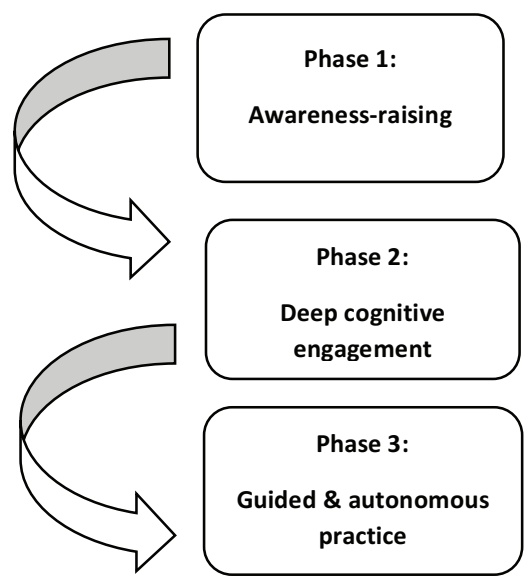

- Metapragmatic explanations \& corpus consultation

- Focused noticing \& contextualized input tasks

- Form-comparison tasks \& corpus consultation

- Speech act analysis \& group discussion

- Written DCTs \& corpus consultation

- Role-plays

- Corrective feedback

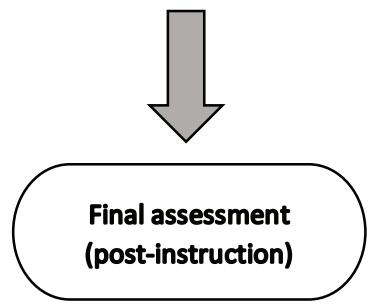

Figure 1: Course overview. 
2. Focused noticing and contextualized input tasks (Bardovi-Harlig \& Vellenga, 2012). In this activity, each student received three booklets with six multipleturn written discourse completion tasks (WDCTSs; Ishihara \& Cohen, 2010) based on scenarios similar to those used for the role-plays during the initial assessment. An example of one of the WDCT can be seen in Figure 2.

During this activity, the students were instructed to carefully read the scenario of each WDCT in their booklets and pay close attention to the responses provided by the native speakers ("you-responses"). Next, they identified and underlined any word combinations that sounded formulaic. In order to stimulate focused noticing, pragmatic factors were made salient to the students by means of typographical enhancement.

\section{Phase 2}

1. Form-comparison and corpus consultations. Once the students had identified what they thought were pragmatic formulas, each student was instructed to compare their answers with pragmatic formulas from the NSC (Zavialova, 2016). These formulas were presented in the two lists the students received in Phase 1. Some examples of pragmatic formulas the students were expected to identify in the Interacting with management scenario (Figure 1) include:

\section{Interacting with management (formal context)}

Scenario: Your manager is asking you to stay for several extra hours after work today. However, you have an important appointment scheduled with your family doctor. How would you explain the reason for your inability to stay in a polite way?

Manager: Hi ... (name)! Would you be able to stay for some extra time today after work? We really need to finish that report.

You: No, I am sorry, I have a doctor's appointment after work.

Manager: Oh, that's a pity. Do you think you can still reschedule your appointment? I would really appreciate it if you could stay with us today.

You: Unfortunately, I can't. I've been waiting for over a month to see the doctor.

Manager: Okay, I see. I understand you have to take care of your health first. I will e-mail you the details of our meeting later today then.

You: Thank you for understanding. I will make sure to check for your e-mail after my appointment.

Figure 2: An example of a WDCT from the booklet. 
- No, I am sorry, I have a

- Unfortunately, I can't (refusal)

- Thank you for understanding (thanking)

The objective of this activity was to draw students' attention to both form and function of the target pragmatic formulas as well as their continuous (fixed) or discontinuous (semi-fixed) nature (Wray, 2002).

2. Speech act analysis and group discussion. During this activity, the students completed two exercises that incorporated both refusal and thanking pragmatic formulas (see Figure 3). Exercise 1 focused on pragmatic meanings of the pragmatic formulas. In this exercise, the students were presented with 20 pragmatic formulas from the NSC (Zavialova, 2016) and instructed to discuss in pairs the communicative meanings of the formulas as well as potential social context(s) in which they may occur. I facilitated the discussion, and also provided the students with metapragmatic explanations when the need arose. Exercise 2 focused on semantic formulas that underlie speech acts of refusal and thanking. ${ }^{7}$ The students received metapragmatic explanations about the concept of semantic formula in lay language. In particular, I used

\section{Exercise 1. Communicative meanings}

Instructions: How do you understand the meaning of the following expressions (formulas)? Work with your partner and explain each expression below in your own words. Write down your explanation next to each formula. Can you think of an example of a situation where these expressions may be used?

I can't make it

That's so sweet of you

\section{Exercise 2. Communicative strategies}

Instructions: Read speakers' responses below. Can you explain what communicative strategies the speakers used in each response? Use your own words.

Response Speaker's strategies

I'm sorry, I won't be able to make it. Hopefully, we can get together soon.

Wow, I am so surprised! Thank you very much! So thoughtful of you! I will not disappoint you.

Figure 3: A sample of two exercises. 
the term "speaker's communicative strategy" instead of "semantic formula" when referring to speech act components. For this analysis, the students were presented with 18 responses that contained both refusal and thanking formulas. The students worked in pairs to analyze these responses in terms of semantic formulas. To this end, the students were instructed to divide each speech act into components and assign a semantic formula (communicative strategy) corresponding to each component as in the following example:

That sounds like a great plan [statement of positive opinion], but ...

I'm satisfied with my current plan [excuse].

In other words, the students had to decide what communicative intention a speaker expressed by means of various pragmatic formulas. Finally, the students were encouraged to exchange their findings with their peers and the instructor. The main objective of these exercises was to give the students an opportunity to process the target pragmatic formulas on a deeper cognitive level as well as facilitate acquisition of both linguistic forms and pragmatic functions of the target formulas.

\section{Phase 3}

1. Written DCTs and corpus consultations. Under my supervision, each student completed six multiple-turn WDCTs (Ishihara \& Cohen, 2010) based on scenarios similar to those used in Phase 1 . The students were encouraged to refer to the examples from the NSC (Zavialova, 2016) when selecting appropriate refusal and thanking formulas for the WDCTs' completion in order to facilitate automaticity and accuracy of production. Once the students had completed the WDCTs, they shared their responses with the full group. If the students used pragmatically inappropriate formulas (e.g., too formal or not formal enough) or grammatically inaccurate formulas (e.g., "That's great, but I am not really need it" instead of "That's great but I don't really need it"), I provided the students with corrective feedback in the form of pragmalinguistic recasts (Martínez-Flor \& Fukuya, 2005). Particular attention was paid to those pragmatic formulas that contained complex grammatical structures (e.g., use of gerunds, use of prepositions, modals "can" and "be able to"), as such formulas proved to be the most problematic during the initial assessment.

2. Role-plays. In this activity, the students were presented with three refusal and three thanking scenarios similar to those they reviewed in Phase 1. They were instructed to role-play them in pairs. In addition, they were encouraged to try performing different roles (e.g., a friend, a sales agent, a manager). In this way, it was emphasized that different registers (formal vs. informal) require different pragmatic formulas. The objective of this activity was to give the students an opportunity to practice using the target pragmatic formulas with fewer constraints in a meaningful context (Ranta \& Lyster, 2018). 


\section{Results and Conclusion}

For the purpose of the final assessment, I employed three volunteer judges - native speakers of English with extensive ESL teaching experience and expertise in applied linguistics. The judges were asked to holistically assess students' performance before and after the instruction on a 5-point Likert scale from very poor (1 point) to very good (5 points). ${ }^{8}$ In particular, the judges were to decide whether and how accurately the students used refusal and thanking pragmatic formulas in their speech. First, the judges were presented with examples of refusal and thanking pragmatic formulas from the NSC (Zavialova, 2016). Next, the judges independently listened to the recordings of each student performing the role-plays before and after the course.

While the students mainly used non-nativelike formulas that contained multiple deviations from the nativelike equivalents during the initial assessment, the results of the final assessment showed a general increase in the number of nativelike formulas. This was consistent with the scores assigned by the judges for students' pre- and post-instruction performance. In the initial assessment, overall scores for the first two students were in the 2.5-3 range (poor/acceptable), whereas in the final assessment these students scored 4 (good) on average for both refusal and thanking speech acts. The other two students, however, were able to improve their scores only for the thanking speech acts, while their scores for the refusal speech acts did not change after the course. Thus, the third student progressed from 3 points (acceptable) in the initial assessment of the thanking speech acts to 4 points (good) in the final assessment. As for the fourth student, she was able to increase her score from 3 to 4.5 (from good to very good) for the thanking speech acts. These mixed results may be explained by several factors. First, the students' proficiency levels ranged from lower-intermediate to upper-intermediate despite the fact that all four students were placed in the same level (CLB 5-6). Such mixedlevel classes are typical for this type of language programs. Second, some speech acts tend to be more formulaic than others and require a wider range of pragmatic formulas (Bardovi-Harlig, 2016). Thus, role-plays involving thanking speech acts may have led to a greater variety of thanking formulas produced by the students.

The description of the course in this article was an attempt to demonstrate how theoretical knowledge about formulaic language and pragmatics can be used to inform lesson or course design as well as strengthen the efficacy of instruction in these two areas. The teaching activities in Phase 1 were aimed at raising students' awareness in a focused and contextualized way. In Phase 2, the instruction focused on stimulating long-term retention of the refusal and thanking pragmatic formulas by engaging the students in activities requiring deep cognitive engagement. Finally, in Phase 3 the students were provided with opportunities to engage in both control and free practice activities. 
The role-plays as well as corpus consultations tasks used in the course could help prepare students for dealing with challenges associated with realworld language use and could be incorporated into task-based lessons. Moreover, both initial and final assessment became integral parts of the course. Such procedures can be used by LINC teachers as means of formative assessment, since collecting evidence of students' ongoing progress adequately fits into the requirements of Portfolio-Based Language Assessment (PBLA). I hope that the pedagogical approach suggested here will become a starting point for further classroom research into this area, which is both essential and timely.

\section{The Author}

Alisa Zavialova is a PhD candidate in Applied Linguistics and Discourse Studies at Carleton University. Her research interests centre around formulaic language and pragmatics pedagogy. She currently teaches ESL and EAP in Ottawa.

\section{Notes}

1. Pragmatic competence is an ability to use a second language in a contextually appropriate and linguistically accurate manner.

2. To avoid confusion, hereafter I will use the term formula or pragmatic formula to refer to all formulaic sequences of this kind.

3. Knowledge of linguistic forms and their functional meanings (Taguchi, 2016).

4. A sequence of rhetorical steps taken by a speaker when performing a given speech act.

5. This corresponds to Canadian Language Benchmarks (CLB) levels 5-6.

6. An example of a discontinuous formula.

7. Semantic formulas in refusal speech acts include statements of negative ability (e.g., I can't make it) or statements of regret (e.g., I wish I could come) (Beebe, Takahashi, \& Uliss-Weltz, 1990). Semantic formulas in thanking speech acts include strategies such as thanking + expressing surprise or delight (e.g., Thank you! I am so surprised) or thanking + exaggerating to emphasize the depth of the gratitude (e.g., Thank you! I really appreciate it) (Eisenstein \& Bodman, 1986).

8. The judges were unaware of when the role-plays were recorded.

\section{References}

Bardovi-Harlig, K. (2009). Conventional expressions as a pragmalinguistic resource: Recognition and production of conventional expressions in L2 pragmatics. Language Learning, 59(4), 755795. http://dx.doi.org/10.1111/j.1467-9922.2009.00525.x

Bardovi-Harlig, K. (2012). Formulas, routines, and conventional expressions in pragmatics research. Annual Review of Applied Linguistics, 32, 206-227. Retrieved from http://dx.doi. org/10.1017/S0267190512000086

Bardovi-Harlig, K. (2016). How formulaic is pragmatics? In K. Bardovi-Harlig \& C. FélixBrasdefer (Eds.), Pragmatics and language learning (Vol. 14, pp. 325-339). Honolulu, HI: University of Hawai'i, National Foreign Language Resource Center.

Bardovi-Harlig, K., \& Vellenga, H. E. (2012). The effect of instruction on conventional expressions in L2 pragmatics. System, 40(1), 77-89. Retrieved from http://dx.doi.org/10.1016/j. system.2012.01.004

Beebe, L. M., Takahashi, T., \& Uliss-Weltz, R. (1990). Pragmatic transfer in ESL refusals. In R. Scarcella, E. Andersen \& S. D. Krashen (Eds.), Developing communicative competence in a second language (pp. 55-73). New York: Newbury House. 
Boers, F., Eyckmans, J., Kappel, J., Stengers, H., \& Demecheleer, H. (2006). Formulaic sequences and perceived oral proficiency: Putting a lexical approach to the test. Language Teaching Research, 10(3), 245-261. http://dx.doi.org/10.1191/1362168806lr195oa

Boers, F., Eyckmans, J., \& Stengers, H. (2006). Motivating multiword units: Rationale, mnemonic benefits, and cognitive style variables. EUROSLA yearbook, 6(1), 169-190. http://dx.doi. org/10.1075/eurosla.6.11boe

Boers, F., \& Lindstromberg, S. (2009). Optimizing a lexical approach to instructed second language acquisition. Basingstoke, UK: Palgrave Macmillan. http://dx.doi.org/ 10.1057/9780230245006

Cohen, A. D. (2005). Strategies for learning and performing L2 speech acts. Intercultural Pragmatics, 2(3), 275-301. http://dx.doi.org/10.1515/iprg.2005.2.3.275

Coulmas, F. (1979). On the sociolinguistic relevance of routine formulae. Journal of Pragmatics, 3(3-4), 239-266. https://doi.org/10.1016/0378-2166(79)90033-X

Eisenstein, M., \& Bodman, J. (1986). 'I very appreciate': Expressions of gratitude by native and non-native speakers of American English. Applied Linguistics, 7(2), 167-185. Retrieved from https://doi.org/10.1093/applin/7.2.167

Fukuya, Y. J., \& Clark, M. K. (2001). A comparison of input enhancement and explicit instruction of mitigators. In L. F. Bouton (Ed.), Pragmatics and language learning (Vol. 10, pp. 111-130). Urbana-Champaign, IL: University of Illinois, Division of English as an International Language Intensive English Institute: University of Illinois at Urbana-Champaign.

Fukuya, Y. J., \& Zhang, Y. (2002). Effects of recasts on EFL learners' acquisition of pragmalinguistic conventions of request. Second Language Studies, 21(1), 1-47. Retrieved from http:// hdl.handle.net/10125/40652

Hajer, A., Kaskens, A-M., \& Stasiak, M. (2007). Language Instruction for Newcomers to Canada: LINC 5-7 curriculum guidelines. Toronto, ON: Toronto Catholic District School Board. Retrieved from http://atwork.settlement.org/downloads/linc/LINC_Curriculum_ Guidelines_5-7.pdf

Ishihara, N., \& Cohen, A. D. (2010). Teaching and learning pragmatics: Where language and culture meet. Harlow, UK: Pearson Education Limited.

Kasper, G. (2001). Classroom research in interlanguage pragmatics. In K. Rose \& G. Kasper (Eds.), Pragmatics in language teaching (pp. 33-60). Cambridge, UK: Cambridge University Press. https://doi.org/10.1017/CBO9781139524797.013

Kecskes, I. (2010). Situation-bound utterances as pragmatic acts. Journal of Pragmatics, 42(11), 2889-2897. Retrieved from https://dx.doi.org/10.1016/j.pragma.2010.06.008

Kiefer, F. (1996). Bound utterances. Language Sciences, 18(1), 575-587. https://doi.org/10.1016/03880001(96)00035-6

Lindstromberg, S., \& Boers, F. (2008). The mnemonic effect of noticing alliteration in lexical chunks. Applied Linguistics, 29(2), 200-222. https://doi.org/10.1093/applin/amn007

Martínez-Flor, A., \& Fukuya, Y. J. (2005). The effects of instruction on learners' production of appropriate and accurate suggestions. System, 33(3), 463-480. http://dx.doi.org/ 10.1016/j. system.2005.06.007

Martínez-Flor, A., \& Usó-Juan, E. (2006). A comprehensive pedagogical framework to develop pragmatics in the foreign language classroom: The 6Rs Approach. Applied Language Learning, 16(2), 39-63. Retrieved from ERIC database. (EJ1069320)

Pawley, A. (2007). Developments in the study of formulaic language since 1970: A personal view. In P. Skandera (Ed.), Phraseology and culture in English (pp. 3-49). Berlin, Germany: Mouton de Gruyter.

Peters, E. (2012). Learning German formulaic sequences: The effect of two attentiondrawing techniques. Language Learning Journal, 40(1), 65-79. https://dx.doi.org /10.1080/09571736.2012.658224

Ranta, L., \& Lyster, R. (2018). Form-focused instruction. In P. Garrett \& J.-M. Cots (Eds.), The Routledge handbook of language awareness. Abingdon, UK: Routledge. 
Rose, K., \& Kwai-fun, C. N. (2001). Inductive and deductive teaching of compliments and compliment responses. In K. Rose \& G. Kasper (Eds.), Pragmatics in language teaching (pp. 145-170). Cambridge, UK: Cambridge University Press. https://doi.org/10.1017/CBO9781139524797.013

Schmidt, R. W. (1990). The role of consciousness in second language learning. Applied Linguistics, 11(2), 129-158. https://doi-org/10.1093/applin/11.2.129

Taguchi, N. (2016). Contexts and pragmatics learning: Problems and opportunities of the study abroad research. Language Teaching, 51(1), 124-137. https://doi.org/10.1017/ S0261444815000440

Tateyama, Y. (2001). Explicit and implicit teaching of pragmatic routines: Japanese sumimasen. In K. Rose and G. Kasper (Eds.), Pragmatics in language teaching (pp. 200-222). Cambridge: Cambridge University Press. https://doi.org/10.1017/CBO9781139524797.013

Webb, S., \& Kagimoto, E. (2011). Learning collocations: Do the number of collocates, position of the node word, and synonymy affect learning? Applied Linguistics, 32(3), 259-276. https:// doi-org /10.1093/applin/amq051

Weinert, R. (2010). Formulaicity and usage-based language: Linguistic, psycholinguistic and acquisitional manifestations. In D. Wood (Ed.), Perspectives on formulaic language: Acquisition and communication (pp. 1-20). London, UK: Continuum.

Wood, D. (2015). Fundamentals of formulaic language: An introduction. London, UK: Bloomsbury.

Wray, A. (2000). Formulaic sequences in second language teaching: Principle and practice. Applied Linguistics, 21(4), 463-489. https://doi.org /10.1093/applin/21.4.463

Wray, A. (2002). Formulaic language and the lexicon. Cambridge, UK: Cambridge University Press. https://doi.org/10.1017/CBO9780511519772

Yoshimi, D. R. (2001). Explicit instruction and JFL learners' use of interactional discourse markers. In K. Rose \& G. Kasper (Eds.), Pragmatics in language teaching (pp. 223-244). Cambridge, UK: Cambridge University Press. https://doi.org/10.1017/CBO9781139524797.013

Zavialova, A. (2016). Explicit instruction of situation-specific formulaic expressions and second language pragmatic competence: A classroom intervention study. In H. M. McGarrell \& D. Wood (Eds.). Contact: Special Research Symposium Issue, 42(2), 82-104. Toronto: TESL Ontario. Retrieved from http://www.teslontario.net/uploads/publications/researchsymposium/ ResearchSymposium2016.pdf 